TI 2011-034/ 1

Tinbergen Institute Discussion Paper

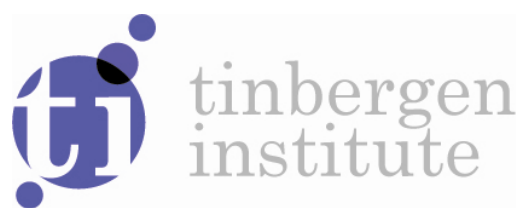

\title{
On the Role of Pre-Determined Rules for HRM Policies
}

Silvia Dominguez-Martinez',3

Otto H. Swank2,3

1 University of Amsterdam;

2 Erasmus University Rotterdam;

3 Tinbergen Institute. 
Tinbergen Institute is the graduate school and research institute in economics of Erasmus University Rotterdam, the University of Amsterdam and VU University Amsterdam.

More TI discussion papers can be downloaded at http://www.tinbergen.nl

Tinbergen Institute has two locations:

Tinbergen Institute Amsterdam

Gustav Mahlerplein 117

1082 MS Amsterdam

The Netherlands

Tel.: +31(0)205251600

Tinbergen Institute Rotterdam

Burg. Oudlaan 50

3062 PA Rotterdam

The Netherlands

Tel.: +31(0)10 4088900

Fax: +31(0)104089031

Duisenberg school of finance is a collaboration of the Dutch financial sector and universities, with the ambition to support innovative research and offer top quality academic education in core areas of finance.

DSF research papers can be downloaded at: http://www.dsf.nl/

Duisenberg school of finance

Gustav Mahlerplein 117

1082 MS Amsterdam

The Netherlands

Tel.: +31(0)20 5258579 


\title{
On the Role of Pre-Determined Rules for HRM Policies
}

\author{
Silvia Dominguez-Martinez*and Otto H. Swank ${ }^{\dagger}$
}

\begin{abstract}
Using simple game-theoretical models, this paper studies the role of predetermined rules for HRM policies. We consider a model in which HRM decisions affect employees' self-images and thereby their motivation. We show that in the absence of written rules, managers are too reluctant (1) to differentiate between employees on the basis of their abilities, and (2) to terminate employment of employees on probation. Generally, organizations benefit from committing to strict rules for various HRM practices.
\end{abstract}

Key words: Rules, human resource management policies, self-image, motivation.

JEL Classification: M5, D82, D83

*University of Amsterdam and Tinbergen Institute. E-mail: S.DominguezMartinez@uva.nl

${ }^{\dagger}$ Erasmus University Rotterdam and Tinbergen Institute. E-mail: swank@ese.eur.nl 


\section{Introduction}

An important question in almost any organization is to what extent decisions on the career paths of employees should be based on pre-determined rules or should be left to the discretion of managers. One reason to give discretion to managers is that their knowledge about the performances and abilities of employees enable them to tailor their decisions to the information they have. A well-known problem of giving discretion is shirking among managers. For example, dismissing an employee is often a painful process, both for the manager and for the employee being fired. Managers may tend to keep less competent employees to avoid the trouble of firing them. Likewise, it may be hard for managers to differentiate employees on the basis of their abilities. It is easier to say to John that he did a better job than Pete than to say to Pete that he did a worse job than John. An implication is that it might be easier for a manager to abstain from differentiating on the basis of abilities, for instance, by basing promotion decisions (or allocations of tasks) on seniority. Nevertheless, it may be in the interest of an organization that incompetent employees are fired, and that tasks are allocated on the basis of relative abilities. Another possible advantage of pre-determined rules is that in the absence of them, managers may be more prone to favoritism (see Prendergast and Topel, 1993 and 1996).

In the present paper, we point out that apart from moral hazard problems that may arise from giving discretion to managers there exists another rationale for predetermined rules for HRM practises. We show that in environments where HRM decisions affect employees' self-images and thereby their motivation, the absence of rules makes managers too reluctant to dismiss less competent employees and too reluctant to differentiate employees on the basis of abilities. The reason is that under discretion a manager makes decisions on the basis of realized characteristics of employees. Rules, however, are based on all possible realized characteristics. More specifically, under

discretion HRM practices are based on their incentives effects on employees at the margin, whereas under predetermined rules HRM practices are based on their effects on all employees.

We derive our results from models that are based on three important assumptions. First, effort and ability are complementary. This is more or less a standard assumption. Second, employees are uncertain about their own abilities. Third, HRM decisions 
contain information about the employees' abilities. The last two assumptions can be justified by a huge literature in social psychology that shows that people are uncertain about a wide range of abilities or skills (see, for example, Ackerman, Beier and Bowen, 2002, and Kruger, 1999). People form a view of themselves, in general, and of their abilities in particular, through three main sources (Aronson, Wilson, and Akert, 2005). One source is introspection. A second source is experience (learning by doing), and the third source is how they are perceived and treated by others. For the present paper, this third source is essential. Key in our model is that a manager's decisions on employees' careers may contain information about how the manager perceives employees. As a consequence, these decisions may influence employees self-perceptions, and in turn their motivation. In situations where ability and effort are complementary, employees with a more positive self-image tend to expend more effort.

In the present paper we show how two HRM practices impact on employees' performance through their effects on their self-images. We first analyze a model in which a manager places new employees in probation. After having learnt an employee's ability in a probationary period, the manager decides whether to replace the employee or to keep him. In this model, the manager follows a simple threshold strategy. Keep the employee if and only if his ability exceeds a threshold. Obviously, the decision about the future of the employee contains information about his ability. Giving an employee a permanent position boosts his confidence and may improve his performance. We show that this effect may induce managers to be too lenient. Managers give permanent positions to employees who (in expected terms) are less able than their possible substitutes. More importantly, we show that a manager would benefit if, before she knows the ability of the agent, she could commit to a stricter threshold. This result suggests the need for clear guidelines stipulating the conditions under which employees are offered long-term positions. Some universities use such guidelines for tenure decisions.

The second HRM practice we analyze is differentiation between employees on the basis of their relative abilities. Differentiation can take various forms. For example, a manager may promote Pete instead of John. She may give more attention to Pete than to John, or give Pete nicer tasks. A manager may also abstain from differentiation on the basis of abilities. Boring tasks can be alternated with more challenging tasks, and promotion can be based on seniority. We discuss the model of Crutzen, Swank and 
Visser (2010) that analyzes how a manager's differentiation decision affects employees' self-image and effort decisions. We show that differentiation boosts one employee's self-image at the cost of the other employee's self-image. A manager differentiates if Pete is much more able than John, and vice versa. If Pete's ability is close to John's, their manager treats them equally. The main result of this section is that if managers could commit to a differentiation strategy, they would differentiate for much wider ranges of abilities. As with the decision to keep or replace employees, with differentiation decisions (promotion, allocating tasks, etc.) in expected terms organizations benefit from guidelines that stipulate the conditions under which the manager should differentiate between employees.

In the third part of the paper, we present a model in which a manager supervising two employees can conduct both HRM policies. The most striking result from this model is that the manager may decide to keep a completely unproductive employee even though she can replace him with a productive new employee. The reason for this, for us, surprising result is that by sending an employee away, a manager gives up the possibility of differentiation on ability. John's perception of his ability may be more positive if he is promoted and Pete is allowed to stay in the organization than when he his promoted and Pete is fired. Also, in the model where the manager can conduct both HRM policies, the manager often abstains from differentiation and firing employees. A manager who can commit himself would be far less lenient to terminate employment during probation and would differentiate much more often.

As discussed above, an important idea behind the models developed in this paper is that people increase their self-knowledge by viewing themselves through the eyes of others. This idea is well-known to social-psychologists who refer to it as the "lookingglass self". Benabou and Tirole (2003) applied the looking-glass self to management. They show, among other things, that giving an individual a challenging task signals confidence and consequently motivates (see also Ishida, 2006, and Swank and Visser, 2007). Interim performance feedback may also affect employees motivation (see, for example, Ertac, 2005, and Ederer, 2010). Like in these papers, in our paper HRM decisions affect employees' incentives through the looking-glass self. However, the emphasis of our paper is on the question whether organization may benefit from commitment to rules as to HRM policies. More remotely, our paper is related to the older literature on rules versus discretion (see Kydland and Prescott, 1977). 
We think that our paper makes both a positive and a more normative contribution to the existing literature. From a positive point of view, our model explains why in the absence of clear guidelines at the end of a probationary period employees may get the benefit of the doubt. Moreover, our model explains seniority based promotion rules and why managers tend to assign relatively uniform performance ratings to employees (see Brickley, Smith and Zimmerman, 2009). Our results are also consistent with Bewley (1999) who after more than 300 interviews with businesspeople was surprised by the extent to which "employers chose to impose bureaucratic constraints on their decision making" (Bewley, 1999, p.65). From a normative point of view, this paper demonstrates the potential importance of guidelines for all kind of HRM practices.

This paper is organized as follows. The next section presents the model in which a manager makes two types of HRM decisions, keeping or replacing an employee, and differentiating between employees. Section 3 presents the equilibrium of the model in which the manager only decides to keep employees or to replace them. Next, Section 4 presents the equilibrium in which the manager chooses to differentiate employees or to treat them equally. Section 5 presents equilibria of the total model. Sections 3-5 consist of two parts. In the first part, HRM decisions are left to the discretion of managers. In the second part, HRM decisions are based on rules specified in advance. Section 6 concludes.

\section{The Model}

The model describes how management of employees influences employees' self-images, and in turn effort and output. We consider a manager (she) who runs a unit of two employees, $i=\{1,2\}$. Output of the unit depends on the effort levels employees choose, $e_{1}$ and $e_{2}$, and on their abilities, $a_{1}$ and $a_{2}$. The individual output levels equal $y_{i}=a_{i} e_{i}$. Key in our model is that the manager has a more accurate view of the employees' abilities than the employees themselves. One can best think of our model as a two-period model. In the first period, two new employees enter the unit. No real production takes place, but thanks to years of experience with subordinates the manager can accurately assess the employees' abilities. As a result, at the end of period 1 the manager knows $a_{1}$ and $a_{2}$, while the employees only know that $a_{1}$ and $a_{2}$ are iid random variables with a uniform distribution on $[0,1]$. 
The manager is responsible for human resource management. In our model, HRM can be divided in two facets. First, the manager can keep an employee or replace him with another one. When the manager replaces employee $i, r_{i}$, the new employee, $i^{\text {new }}$, has an expected ability equal to $z$. With a slight abuse of notation, we write $E\left(a_{i^{\text {new }}} \mid r_{i}\right)=z$, where $E$ is the expectation operator. For simplicity, we assume that the manager does not have the time to learn the new employee's strengths and weaknesses, implying that the new employee and the manager are equally well informed about the new employee's ability. We assume that $z \leq \frac{1}{2}$. The implication is that the expected ability of the new employee is not higher than the expected ability of an employee present in period 1. Second, in case the manager decides that both employees stay in her unit, she can choose between (i) treating both employees equally, and (ii) to favor one over the other. In practice, there are many ways in which a manager may differentiate between employees. She can give one employee more challenging tasks, more guidance, a larger office, etc. In this paper, we are agnostic about the specific form of differentiation. We simply model it as a message. One implication is that it does not directly affect the productivity of employees. However, a message may contain information about employees' abilities. As we will show, through this channel, differentiating or abstaining from it affects effort. All in all, a manager can choose among six messages. The first column of Table 1 describes these messages. The second column of Table 1 shows how we denote them.

\begin{tabular}{ll}
\hline Possible messages & notation \\
\hline Facet 1 Probation & \\
\hline Replace both 1 and 2 & $m\left(a_{1}, a_{2}\right)=r_{1+2}$ \\
\hline Keep 1 replace 2 & $m\left(a_{1}, a_{2}\right)=r_{2}$ \\
\hline Keep 2 replace 1 & $m\left(a_{1}, a_{2}\right)=r_{1}$ \\
\hline Keep 1 and 2, no differentiation & $m\left(a_{1}, a_{2}\right)=1 \sim 2$ \\
\hline
\end{tabular}

\section{Facet 2 Differentiation}

Keep both 1 and 2, favor 1 over $2 \quad m\left(a_{1}, a_{2}\right)=1 \succ 2$

Keep both 1 and 2, favor 2 over $1 \quad m\left(a_{1}, a_{2}\right)=2 \succ 1$

Table 1: Possible actions of the manager

Output is divided by the manager and the employees who eventually do the work. Each agent bears the cost of his own effort. To drive home the main points of our paper 
in the simplest way we assume a quadratic cost of effort function $\left(c\left(e_{i}\right)=\frac{1}{2} e_{i}^{2}\right)$. The payoff to the manager equals $(1-\lambda)\left(y_{1}+y_{2}\right)$. The payoff to employee $i$ (if working in period 2) equals $\lambda y_{i}-\frac{1}{2} e_{i}^{2}$. The payoff to an employee who is replaced equals zero.

We solve the model by identifying a Perfect Bayesian equilibrium in which (i) each employee's effort strategy is optimal given the manager's HRM strategy and the employee's beliefs about his ability; (ii) the manager's HRM strategy is optimal given the employees' effort strategies and the employees' beliefs about their ability; and (iii) beliefs are updated according to Bayes' rule. The manager's strategy maps employees abilities into a message, $m\left(a_{1}, a_{2}\right)$. Employee $i$ 's effort strategy maps a message into an effort level, $e_{i}(m)$.

We divide the analysis in four parts. First, below we derive the effort employee $i$ exerts, given $m$ and his beliefs about his ability. Second, in the next section, we restrict the message set of the manager to $M=\left\{r_{1+2}, r_{1}, r_{2}, 1 \sim 2\right\}$. We refer to this model as the Probation Model. In the Appendix, we deal with a more general version of the Probation model. The manager hires an employee for a probationary period (period 1). If his ability is sufficiently high, the employee is also hired in the second period. Third, in Section 4 we present the analysis of the model in which the manager's message set is restricted to $M=\{1 \sim 2,1 \succ 2,2 \succ 1\}$. A more general version of this model, to which we refer as the model of differentiation, is fully discussed in Crutzen, Swank and Visser (2010). Finally, we identify Perfect Bayesian Equilibria for the entire game. As there are no closed-form solutions for this game, we rely on numerical examples.

As discussed above, the essential feature of our model is that the manager has superior knowledge about the employees' abilities. In equilibrium, the manager's choices may contain information that is relevant for the employees. For example, as we discuss below, under certain conditions an employee who is allowed to stay may infer that his ability exceeds a certain threshold. To focus on the transmission of information from the manager to the employees through HRM policy, we have kept the effort decision of the employees as simple as possible. In the three models discussed below, the effort decision of employee $i$ results from maximizing $E\left(\lambda a_{i} e_{i}-\frac{1}{2} e_{i}^{2} \mid m\right)$, yielding

$$
e_{i}(m)=\lambda \hat{a}_{i}(m)
$$


where $\hat{a}_{i}(m)$ is the expectation of $a_{i}$, conditional on message $m .{ }^{1}$ Note that $e_{i^{\text {new }}}\left(r_{i}\right)=$ $e_{i^{\text {new }}}\left(r_{1+2}\right)=\lambda z$. Furthermore note that effort and ability are complements. The higher is $\hat{a}_{i}(m)$, the higher is effort. The implication is that the manager wants employees to have positive self-images.

In the model presented above, the manager sends a message after she has observed $a_{1}$ and $a_{2}$. The model thus describes a situation where the manager has full discretion. An alternative setting is that HRM rules are set in advance, that is before $a_{1}$ and $a_{2}$ are observed. For example, one rule may stipulate the conditions in terms of $a_{i}$ under which a manager may keep employee $i$. Of course, such rules only make sense if the manager is committed to follow them. For all models, we also derive the equilibria under commitment.

\section{Equilibrium of the Probation Model}

In this section, we assume that $M \in\left\{r_{1}, r_{2}, r_{1+2}, 1 \sim 2\right\}$. The manager has to decide whether the employees may stay or not. We refer to this model as the probation model. Clearly, the more able an employee is, the higher is his value for the manager. As a consequence, it is optimal for the manager to follow a threshold strategy. Given the posteriors $\hat{a}_{1}(m)$ and $\hat{a}_{2}(m)$, and given (1), we must determine for which $\left(a_{1}, a_{2}\right)$ the manager prefers a certain message to the other messages. For each pair of messages the following equations denote the values of $a_{1}$ and $a_{2}$ for which the manager is indifferent between two messages

$$
\begin{aligned}
2 z^{2} & =z^{2}+a_{1} \hat{a}_{1}\left(r_{2}\right) \\
2 z^{2} & =z^{2}+a_{2} \hat{a}_{2}\left(r_{1}\right) \\
2 z^{2} & =a_{1} \hat{a}_{1}(1 \sim 2)+a_{2} \hat{a}_{2}(1 \sim 2) \\
z^{2}+a_{1} \hat{a}_{1}\left(r_{2}\right) & =a_{1} \hat{a}_{1}(1 \sim 2)+a_{2} \hat{a}_{2}(1 \sim 2) \\
z^{2}+a_{2} \hat{a}_{2}\left(r_{1}\right) & =a_{1} \hat{a}_{1}(1 \sim 2)+a_{2} \hat{a}_{2}(1 \sim 2)
\end{aligned}
$$

Equation (2) shows the condition under which the manager is indifferent between sending both employees away on the one hand, and sending only employee 2 away on the

\footnotetext{
${ }^{1}$ The employee's expected payoff exceeds zero, implying that an employee who is allowed to stay also wants to stay. In other words, the participation contraint is always satisfied.
} 
other. This condition implies that if $a_{1}$ exceeds a threshold $a_{1}>\frac{z^{2}}{\hat{a}_{1}\left(r_{2}\right)}, r_{2}$ leads to a higher payoff than $r_{1+2}$. Equation (3) yields a similar threshold value for $a_{2}$. Equation (4) shows the condition under which the manager is indifferent between keeping both employees and sending both employees away. Equation (5) gives the condition under which the manager is indifferent between keeping only member 1 and keeping both members. Equation (6) gives this condition for employee 2. Using (3) and (5), and imposing symmetry $\left[\widehat{a}_{1}(1 \sim 2)=\widehat{a}_{2}(1 \sim 2)\right.$ and $\widehat{a}_{1}\left(r_{1}\right)=\widehat{a}_{2}\left(r_{2}\right)$, and employees are treated in the same way $]^{2}$, we obtain that $\hat{a}_{1}\left(r_{2}\right)=\hat{a}_{2}\left(r_{1}\right)=\hat{a}_{1}(1 \sim 2)=\hat{a}_{2}(1 \sim 2)$, so that $a_{1} \hat{a}_{1}(1 \sim 2)=z^{2}$. Hence, the expected ability of an employee who is allowed to stay in the organization is independent of what the manager decides about the other employee. In other words, employee $i$ may stay if $a_{i}$ exceeds a threshold, and this threshold does not depend on $a_{-i}$. Denote this threshold by $a^{*}$. Bayes' rule implies that $\hat{a}_{1}\left(r_{2}\right)=E\left(a_{1} \mid a_{1}>a^{*}\right)=\frac{1}{2}\left(1+a^{*}\right)$. Using (2), it follows that

$$
\begin{gathered}
2 z^{2}=z^{2}+a^{*} \frac{1}{2}\left(1+a^{*}\right), \text { implying } \\
a^{*}=\frac{1}{2}\left(\sqrt{1+8 z^{2}}-1\right)
\end{gathered}
$$

Equation (7) shows that the more able is the potential substitute for employee $i$, the higher is the threshold $a^{*}$. Somewhat more surprising is that for $0<z<1, a^{*}<z$. This means that the manager may keep an employee, even though she can replace him with a more able employee. To understand this result suppose that $a^{*}=z$. Then, from an ability point of view, the manager is indifferent between keeping the employee and sending him away. However, a new employee would exert less effort than an employee who is allowed to stay $\left[z<\frac{1}{2}\left(1+a^{*}\right)\right.$ if $\left.a^{*}=z\right]$. To compensate for this effect, $a^{*}$ must be lower than $z$. Proposition 1 summarizes the discussion above.

Proposition 1 An equilibrium of the probation model exists in which

(i) if $m=r_{1+2}$ or $m=r_{i}, e_{i^{\text {new }}}=\lambda z$;

(ii) if $m=1 \sim 2$, or $m=r_{-i}, e_{i}=\lambda \hat{a}_{i}(1 \sim 2)=\lambda \hat{a}_{i}\left(r_{-i}\right)$;

(iii) the manager keeps employee $i$ if $a_{i}>a^{*}=\frac{1}{2}\left(\sqrt{1+8 z^{2}}-1\right)$, with $a^{*}<z$, and replaces $i$ otherwise;

(iv) $\hat{a}_{i}\left(r_{-i}\right)=\hat{a}_{i}(1 \sim 2)=\frac{1}{4}\left(\sqrt{1+8 z^{2}}+1\right) ; \hat{a}_{i}\left(r_{i}\right)=\hat{a}_{i}\left(r_{1+2}\right)=\frac{1}{4}\left(\sqrt{1+8 z^{2}}-1\right)$

\footnotetext{
${ }^{2}$ The next section deals with differentiation.
} 


\subsection{Commitment}

We now derive the manager's HRM strategy if before she observes the employees' abilities she stipulates the conditions under which each employee is allowed to stay. Let $a_{c, i}^{*}$ denote the optimal threshold for member $i$ under commitment. When determining the thresholds, the manager anticipates the employees' effort strategies. The expected payoff to the manager when choosing the thresholds equals

$$
\begin{aligned}
U_{M}\left(a_{c, 1}^{*}, a_{c, 2}^{*}\right) & =\lambda(1-\lambda) \sum_{i=1}^{2}\left(\operatorname{Pr}\left(a_{i} \leq a_{c, i}^{*}\right) z^{2}+\operatorname{Pr}\left(a_{i}>a_{c, i}^{*}\right) \frac{1}{4}\left(1+a_{c, i}^{*}\right)^{2}\right) \\
& =\lambda(1-\lambda) \sum_{i=1}^{2}\left(a_{c, i}^{*} z^{2}+\left(1-a_{c, i}^{*}\right) \frac{1}{4}\left(1+a_{c, i}^{*}\right)^{2}\right)
\end{aligned}
$$

Maximizing (8) with respect to $a_{c, i}^{*}$ yields

$$
a_{c, i}^{*}=\frac{2}{3} \sqrt{3 z^{2}+1}-\frac{1}{3}
$$

Straightforward calculations show that $a_{c, i}^{*}>z \cdot{ }^{3}$ Thus, under commitment, if $z<$ $a_{i} \leq a_{c, i}^{*}$, the manager replaces employee $i$ even though the new employee is less able. To understand the intuition behind this result, consider the extreme case that $z=0$. Equation (9) shows that in that case, the manager should replace employee $i$ if $a_{c, i}^{*}<$ $\frac{1}{3}$. Clearly, ex post, this is a sub-optimal action. There is a clear cost of replacing a productive person with a completely unproductive person. The benefit of a high threshold lies in highly able persons exerting more effort. It is much more important that highly able employees have a positive self-esteem than that mediocre employees have a positive self-esteem. For this reason, the manager is willing to sacrifice output in case employees turn out to be mediocre in return of higher output if employees turn out to be very able.

The main difference between the non-commitment and the commitment case is that in the non-commitment case the manager provides incentives to the marginal employee, while in the commitment case the manager provides information to all employees. More

\footnotetext{
$3 \frac{2}{3} \sqrt{3 z^{2}+1}-\frac{1}{3}>z \rightarrow 12 z^{2}+4>9 z^{2}+6 z+1 \rightarrow 3(z-1)^{2}>0$, which is always true.
} 
specifically, in the non-commitment case, the manager decides whether or not to keep an employee, given the employee's ability and given the inferences the employee draws from the manager's decision. In the commitment case, by contrast, the manager takes into account the consequences of her HRM decisions for the inferences employees draw. Moreover, in the commitment case HRM decisions are made with a view on influencing all types of employees rather than on influencing a single type.

Proposition 2 Suppose that the manager can commit herself to an HRM strategy before she observes the employees abilities. Then, an equilibrium exists in which

(i) if $m=r_{1+2}$ or $m=r_{i}, e_{i^{n e w}}=\lambda z$;

(ii) if $m=1 \sim 2$, or $m=r_{-i}, e_{i}=\lambda \hat{a}_{i}(1 \sim 2)=\lambda \hat{a}_{i}\left(r_{-i}\right)$;

(iii) the manager keeps employee $i$ if $a_{i}>a_{c, i}^{*}=\frac{2}{3} \sqrt{3 z^{2}+1}-\frac{1}{3}$, with $a_{c, i}^{*}>z$, and replaces $i$ otherwise;

(iv) $\hat{a}_{i}\left(r_{-i}\right)=\hat{a}_{i}(1 \sim 2)=\frac{1}{3}\left(\sqrt{3 z^{2}+1}+1\right) ; \hat{a}_{i}\left(r_{i}\right)=\hat{a}_{i}\left(r_{1+2}\right)=\frac{1}{3} \sqrt{3 z^{2}+1}-\frac{1}{6}$

Proposition 1 and 2 can be translated into practical terms as follows. Many firms hire employees initially on a temporary basis. Those who perform well get a permanent position. In the absence of clear guidelines about the conditions under which employees should be offered a more permanent position, managers tend to be (too) lenient. The focus is on the cost and benefit of offering this particular employee a permanent position. Employees who can be replaced by more able employees are allowed to stay. Guidelines, stipulating the conditions under which employees are offered a permanent position, by contrast, will be quite strict. They may even seem unfair to the individual employee. For example, the guidelines sometimes lead a manager not to a offer a permanent contract to an employee who performs above average. The reason that rules are strict is that they do not only incorporate the costs and benefits of giving a permanent position to a single employee, but incorporate the costs and benefits of all types of employees.

In this section we have derived the equilibrium for a simple probation model. In the Appendix we consider a more general version of the probation model. We show that results do not depend on the specific form of the distribution of abilities. Furthermore we show that the results also hold if we consider a more general utility function. 


\section{A Model of Differentiation}

In this section we focus on the case that the manager can send three messages: $M \in\{1 \succ 2,1 \sim 2,2 \succ 1\}$. The manager cannot replace employees as in the previous section. Instead she can compare employees on the basis of their abilities. We assume that $1 \succ 2(2 \succ 1)$ means that employee $1(2)$ is more able than employee 2 (1). Message $1 \sim 2$ means that employee 1 and 2 are more or less of the same ability. The exact meanings of messages are determined in equilibrium. We assume that employees understand these meanings.

Given $a_{2}$, the higher is $a_{1}$, the stronger is the manager's incentive to send $1 \succ 2$ rather than $1 \sim 2$ or $2 \succ 1$. Sending $1 \succ 2$ yields a higher payoff to the manager than sending $1 \sim 2$ if

$$
(1-\lambda) \lambda\left[a_{1} \hat{a}_{1}(1 \succ 2)+a_{2} \hat{a}_{2}(1 \succ 2)\right]>(1-\lambda) \lambda\left[a_{1} \hat{a}_{1}(1 \sim 2)+a_{2} \hat{a}_{2}(1 \sim 2)\right]
$$

implying

$$
a_{1}>t a_{2} \text { with } t=\frac{\hat{a}_{2}(1 \sim 2)-\hat{a}_{2}(1 \succ 2)}{\hat{a}_{1}(1 \succ 2)-\hat{a}_{1}(1 \sim 2)}
$$

Likewise, one can show that the manager prefers sending $2 \succ 1$ to sending $1 \sim 2$ is $a_{2}>\frac{1}{t} a_{1}$. The equilibrium of the model is characterized by a value of $t$ implying $t=\frac{\hat{a}_{2}(1 \sim 2)-\hat{a}_{2}(1 \succ 2)}{\hat{a}_{1}(1 \succ 2)-\hat{a}_{1}(1 \sim 2)}$. Proposition 3 presents the unique PBE equilibrium of the model of differentiation in which the manager sends all messages in $M$ with a positive probability.

Proposition 3 An equilibrium of the model of differentiation exists in which

(i) $e_{i}=\lambda \hat{a}_{i}(m)$

(ii) $m=1 \succ 2$ if $a_{1}>t a_{2} ; m=2 \succ 1$ if $a_{1}<\frac{1}{t} a_{2}$ and $m=1 \sim 2$ if $\frac{1}{t} a_{2} \leq a_{1} \leq t a_{2}$ with $t=2+\sqrt{3}$.

(iii) $\hat{a}_{1}(1 \succ 2)=\hat{a}_{2}(2 \succ 1)=\frac{2}{3} ; \hat{a}_{1}(2 \succ 1)=\hat{a}_{2}(1 \succ 2)=\frac{1}{3 t} ; \hat{a}_{1}(1 \sim 2)=\hat{a}_{2}(1 \sim 2)=$ $\frac{1}{2}+\frac{1}{6 t}$.

Proof. Given the manager's message strategy, the posteriors result from

$$
\begin{aligned}
& E\left(a_{1} \mid 1 \succ 2\right)=\frac{\int_{0}^{1} \int_{0}^{\frac{a_{1}}{t}} a_{1} d a_{2} d a_{1}}{\int_{0}^{1} \int_{0}^{\frac{a_{1}}{t}} d a_{2} d a_{1}}=\frac{2}{3} ; \\
& E\left(a_{1} \mid 2 \succ 1\right)=\frac{\int_{0}^{\frac{1}{t}} \int_{a_{1} t}^{1} a_{1} d a_{2} d a_{1}}{\int_{0}^{\frac{1}{t}} \int_{a_{1} t}^{1} d a_{2} d a_{1}}=\frac{1}{3 t}
\end{aligned}
$$


and

$$
E\left(a_{1} \mid 1 \sim 2\right)=\frac{\int_{0}^{\frac{1}{t}} \int_{\frac{a_{1}}{t}}^{a_{1} t} a_{1} d a_{2} d a_{1}+\int_{\frac{1}{t}}^{1} \int_{\frac{a_{1}}{t}}^{1} a_{1} d a_{2} d a_{1}}{\int_{0}^{\frac{1}{t}} \int_{\frac{a_{1}}{t}}^{a_{1} t} d a_{2} d a_{1}+\int_{\frac{1}{t}}^{1} \int_{\frac{a_{1}}{t}}^{1} d a_{2} d a_{1}}=\frac{1}{2}+\frac{1}{6 t}
$$

The manager is indifferent between $m=1 \succ 2$ and $m=1 \sim 2$ if

$(1-\lambda) a_{1} \lambda \widehat{a}_{1}(1 \succ 2)+(1-\lambda) a_{2} \lambda \widehat{a}_{2}(1 \succ 2)=(1-\lambda) a_{1} \lambda \widehat{a}_{1}(1 \sim 2)+(1-\lambda) a_{2} \lambda \widehat{a}_{2}(1 \sim 2)$

This equality can be written as

$$
a_{1}=t a_{2} \text { with } t=\frac{\widehat{a}_{2}(1 \sim 2)-\widehat{a}_{2}(1 \succ 2)}{\widehat{a}_{1}(1 \succ 2)-\widehat{a}_{1}(1 \sim 2)}
$$

Substituting the posteriors into the expression for $t$, and solving for $t$ yields $t=2+\sqrt{3}$. Hence, the locus of pairs $\left(a_{1}, a_{2}\right)$ for which the manager is indifferent between sending $1 \succ 2$ and $1 \sim 2$ is given by the line $a_{1}=(2+\sqrt{3}) a_{2}$. Because of symmetry, the line $a_{1}=\frac{1}{2+\sqrt{3}} a_{2}$ describes the locus of pairs $\left(a_{1}, a_{2}\right)$ for which the manager is indifferent between sending $2 \succ 1$ and $1 \sim 2$.

Figure 1: Manager's message strategy in model of differentiation without commitment

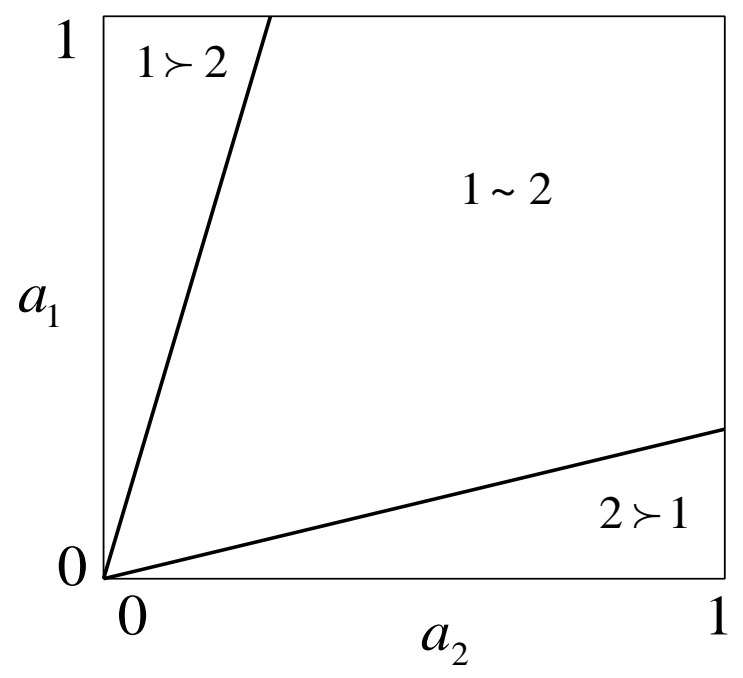

Figure 1 depicts the manager's message strategy. Two points are worth emphasizing. First, the manager treats employees equally especially when employees are relatively able. Second, the manager treats employees equally for a wide range of abil- 
ities. Differentiation is rare (the probability of $m=1 \succ 2$ is equal to $\frac{1}{2} \frac{1}{t} \sim 0.13$ ). Both points are related. An implication of our finding that managers abstain from differentiating when employees are relatively able is that abstaining from differentiation boosts employees' self-images. Initially, the employee's expected ability equals $\frac{1}{2}$. After hearing $1 \sim 2$, the employee's expected ability is just below 0.55. Differentiating boosts the self-image of one agent at the expense of the other. As differentiating occurs when one of the agent has a fairly low ability, the total effect of differentiating on self-images is negative. The upshot is that treating agents equally is optimal unless one agent is really unable relative to the other agent.

The main message of Figure 1 is that managers are highly reluctant to differentiate employees on the basis of their relative abilities. This reluctance stems from a fear of demotivating the employees passed over. Our model thus predicts that managers tend to allocate tasks or give promotions on the basis of factors that are not directly related to relative abilities, such as seniority.

\subsection{Commitment}

In the previous section, we have assumed that the manager sends a message after she has observed the employees' abilities. We now turn to the case where the manager can commit to a message strategy. The manager determines his differentiation strategy before she observes $a_{1}$ and $a_{2}$. We restrict ourselves to a differentiation strategy as in Proposition 3, where the manager sends $m=1 \succ 2$ if $a_{1}>t_{C} a_{2}, m=2 \succ 1$ if $a_{1}<\frac{1}{t_{C}} a_{2}$ and $m=1 \sim 2$ if $\frac{1}{t_{C}} a_{2} \leq a_{1} \leq t_{C} a_{2}$. However, the manager can now commit to a value of $t_{C}$. Proposition 4 presents the equilibrium under commitment.

Proposition 4 Suppose the model of differentiation and that the manager can commit to a differentiation strategy. Then, an equilibrium exists in which

(i) $e_{i}=\lambda \hat{a}_{i}(m)$

(ii) $m=1 \succ 2$ if $a_{1}>t_{C} a_{2} ; m=2 \succ 1$ if $a_{1}<\frac{1}{t_{C}} a_{2}$ and $m=1 \sim 2$ if $\frac{1}{t_{C}} a_{2} \leq a_{1} \leq t_{C} a_{2}$ with $t_{C}=1+\frac{1}{5} \sqrt{10}$.

(iii) $\hat{a}_{1}(1 \succ 2)=\hat{a}_{2}(2 \succ 1)=\frac{2}{3} ; \hat{a}_{1}(2 \succ 1)=\hat{a}_{2}(1 \succ 2)=\frac{1}{3 t_{C}} ; \hat{a}_{1}(1 \sim 2)=\hat{a}_{2}(1 \sim 2)=$ $\frac{1}{2}+\frac{1}{6 t_{C}}$. 
Proof. For the posteriors, see the proof of Proposition (3). The value of $t_{C}$ results from maximizing the manager's expected payoff when choosing $t_{C}$ :

$$
\begin{aligned}
& \quad(1-\lambda) 2 \int_{0}^{1} \int_{0}^{\frac{a_{1}}{t_{C}}}\left(\frac{2}{3} \lambda a_{1}+\frac{1}{3 t_{C}} \lambda a_{2}\right) d a_{2} d a_{1} \\
& +(1-\lambda) \int_{0}^{\frac{1}{t_{C}}} \int_{\frac{a_{1}}{t_{C}}}^{a_{1} t_{C}}\left(\frac{1}{2}+\frac{1}{6 t_{C}}\right) \lambda\left(a_{1}+a_{2}\right) d a_{2} d a_{1} \\
& +(1-\lambda) \int_{\frac{1}{t_{C}}}^{1} \int_{\frac{a_{1}}{t_{C}}}^{1}\left(\frac{1}{2}+\frac{1}{6 t_{C}}\right) \lambda\left(a_{1}+a_{2}\right) d a_{2} d a_{1} \\
& =(1-\lambda) \lambda\left(\frac{1}{18 t_{C}^{3}}-\frac{5}{18 t_{C}^{2}}+\frac{5}{18 t_{C}}+\frac{1}{2}\right)
\end{aligned}
$$

This expression is maximized for $t_{C}=1+\frac{1}{5} \sqrt{10}$

Figure 2: Manager's message strategy in differentiation model with commitment

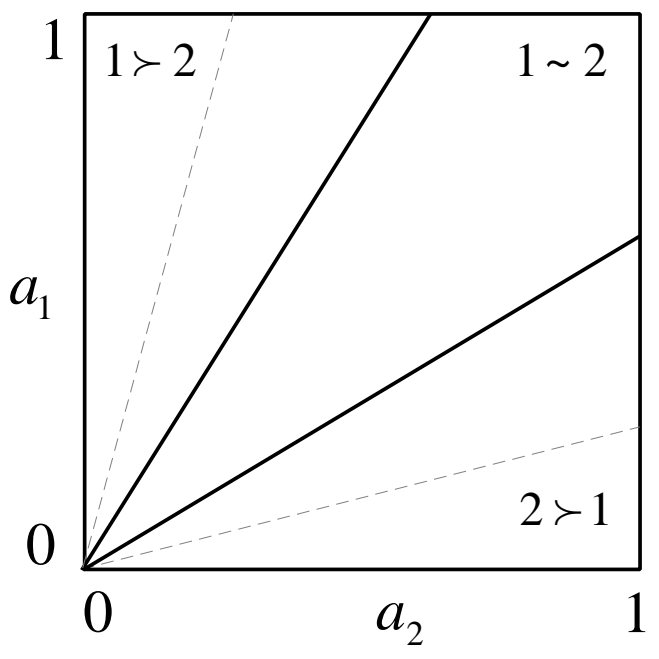

Figure 2 depicts the manager's message strategy under commitment. The dashed line corresponds to the combination of $a_{1}$ and $a_{2}$ for which the manager is indifferent between $1 \succ 2(2 \succ 1)$ and $1 \sim 2$ in the absence of commitment. Clearly, under commitment the manager differentiates for a much wider range of parameters than in the absence of commitment. Under commitment, the probability of differentiation is about 0.61 while in the absence of commitment it is about 0.27 . The reason for this large difference is twofold. First, under commitment the manager takes into account the consequences of her strategy for the employees' self-images. Without commitment, 
the manager takes employees' self images as given. Second, under commitment the manager takes into account the effects of her strategy for all possible pairs of ability levels, while in the absence of commitment the manager only considers the pairs of ability levels for which she is indifferent between differentiating and abstaining from it. Specifically, the larger is the area for which the manager does not differentiate, the smaller is the boost in employees' self-images when abstaining from differentiation. When the manager is able to commit herself, she can ensure that this area does not become too large.

As in Section 3, we have found that manager's practices under commitment differs from practices in the absence of commitment. Again, there is a role for written guidelines. In practice, determining explicit guidelines for differentiation may be more difficult than stipulating the conditions under which employees are allowed to stay. Our results suggest that managers should try to create a culture in which relatively talented employees are put in the spotlight.

\section{Probation and Differentiation}

In this section, we assume that $M \in\left\{r_{1}, r_{2}, r_{1+2}, 1 \sim 2,1 \succ 2,2 \succ 1\right\}$. This means that the manager can replace one or both employees, and if she keeps both employees, she can differentiate between them. As in the probation model, the equilibrium depends on the expected ability of the newcomer, $z$. We can distinguish two broad cases, namely $0 \leq z<\underline{z}$ and $\underline{z} \leq z \leq \frac{1}{2} \cdot{ }^{4}$

CASE 1: $0 \leq z<\underline{z}$

As we will argue below, the most striking feature of the equilibria for low values of $z$ is that the manager never sends the messages $r_{1}$ and $r_{2}$. Therefore, in equilibrium, four messages are sent, $\left\{r_{1+2}, 1 \sim 2,1 \succ 2,2 \succ 1\right\}$. The following equations denote the values of $a_{1}$ and $a_{2}$ for which the manager is indifferent between pairs of these messages.

\footnotetext{
${ }^{4}$ The value of $\underline{z}$ is close to 0.43 .
} 
Because of symmetry, we may limit the analysis to $a_{1} \geq a_{2}$.

$$
\begin{aligned}
2 z^{2} & =a_{1} \widehat{a}_{1}(1 \sim 2)+a_{2} \widehat{a}_{2}(1 \sim 2) \\
2 z^{2} & =a_{1} \widehat{a}_{1}(1 \succ 2)+a_{2} \widehat{a}_{2}(1 \succ 2) \\
a_{1} \widehat{a}_{1}(1 \sim 2)+a_{2} \widehat{a}_{2}(1 \sim 2) & =a_{1} \widehat{a}_{1}(1 \succ 2)+a_{2} \widehat{a}_{2}(1 \succ 2)
\end{aligned}
$$

Equation (10) shows the condition under which the manager is indifferent between sending both employees away on the one hand, and keeping both employees and treating them equally on the other. ${ }^{5}$ Equation (11) gives the condition under which the manager is indifferent between sending both employees away on the one hand, and keeping both employees and differentiating between them on the other. Finally, (12) shows the condition under which the manager is indifferent between treating employees equally and differentiating between them, provided that the employees may stay.

Equations (10-12) are linear lines determining the areas where the principal sends the alternative messages. The slopes and intercepts of the lines depend on the various expected abilities conditional on messages. ${ }^{6}$ In equilibrium, the positions of the lines should lead to consistent conditional expectations of abilities. These conditional expectations, however, are non-linear expressions of slopes and intercepts. As a result, the model cannot be solved analytically. For this reason, we rely on numerical solutions. The numerical analysis showed that for each $z$ a unique equilibrium exists.

Figure 3 presents the equilibria for $z=0.1$ and $z=0.4$. For $z=0.1$, the equilibrium is very similar to the equilibrium of the model of differentiation. Because of the low value of $z$, the principal rarely sends employees away. For $z=0.4$, the area of $a_{1}$ and $a_{2}$ for which the principal sends both employees away is larger. However, also for this relatively high value of $z$, in equilibrium the principal is most likely to keep both employees.

Let us now try to provide an intuition for the result that the manager never sends $r_{1}$ and $r_{2}$. The implication is that the manager wants to keep a completely unable employee if the other employee is fairly able (e.g. send $1 \succ 2$, when $a_{2}=0$ ). Consider the manager's equilibrium strategy presented in Figure 3 for $z=0.1$. Suppose that in this equilibrium the manager sends $r_{2}$ if $\left(a_{1}, a_{2}\right)$ is not in the $r_{1+2}$ area and $a_{2}=0$. In

\footnotetext{
${ }^{5}$ Because of symmetry $\widehat{a}_{1}(1 \sim 2)=\widehat{a}_{2}(1 \sim 2)$.

${ }^{6}$ Equation (10), for example, can be written as $a_{1}=\alpha-\beta a_{2}$ with $\alpha=\frac{2 z^{2}}{\hat{a}_{1}(1 \sim 2)}$ and $\beta=1$.
} 
Figure 3: Probation and Differentiation model: Manager's message strategy for low values of $z$

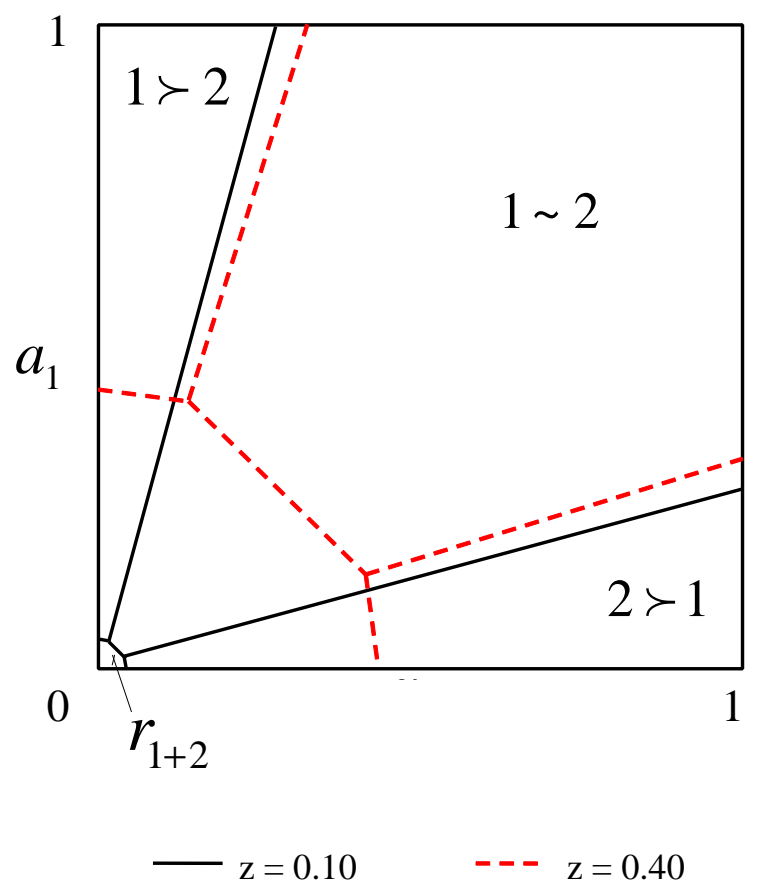

such an equilibrium, the newcomer would not be much more productive (in absolute terms) than the employee being sent away: $\lambda z^{2}$ with $z^{2}=0.01$. Employee 1's expected ability when the manager sends $r_{2}$ would be just above a half. Sending $1 \succ 2$, however, leads to an expected ability of agent 1 just above $\frac{2}{3}$. As a result, member 1 would be much more productive if the manager sends $1 \succ 2$ rather than $r_{2}$ (close to $\lambda\left(\frac{4}{9}-\frac{1}{4}\right)$ ). The benefit of sending $1 \succ 2$ therefore exceeds the cost. Hence, the manager prefers sending $1 \succ 2$ to sending $r_{2}$. Obviously, for high values of $z(z>\underline{z} \sim 0.43)$, the cost of not replacing a completely unproductive employee is much higher. Moreover, if $z$ is high, the message $r_{2}$ would boost employee 1's reputation significantly. As a result, the manager gets an incentive to send $r_{2}$.

CASE 2: $\underline{z} \leq z \leq \frac{1}{2}$

As discussed above, for large values of $z$, it becomes too costly to keep low ability employees just for the purpose of differentiation. For $z>\underline{z}$, the manager sometimes wants to replace the low ability employee and to keeps the high ability employee. Now depending on $a_{1}$ and $a_{2}$ the manager either replaces both, keeps both or decides to keep 
one and replace the other. If the manager keeps both employees, then she additionally decides to differentiate between the employees or not. Besides equation (10-12), the following equations denote the values of $a_{1}$ and $a_{2}$ for which the manager is indifferent between two messages. Because of symmetry we may again focus on $a_{1} \geq a_{2}$.

$$
\begin{aligned}
2 z^{2} & =a_{1} \widehat{a}_{1}\left(r_{2}\right)+z^{2} \\
a_{1} \widehat{a}_{1}\left(r_{2}\right)+z^{2} & =a_{1} \widehat{a}_{1}(1 \sim 2)+a_{2} \widehat{a}_{2}(1 \sim 2) \\
a_{1} \widehat{a}_{1}\left(r_{2}\right)+z^{2} & =a_{1} \widehat{a}_{1}(1 \succ 2)+a_{2} \widehat{a}_{2}(1 \succ 2)
\end{aligned}
$$

Equation (13) shows the condition under which the manager is indifferent between sending both employees away on the one hand, and sending only employee 2 away on the other. Equation (14) and (15) show the condition under which the manager is indifferent between sending only employee 2 away on the one hand, and keeping both employees on the other with no differentiation and differentiation, respectively. Figure 4 shows the manager's equilibrium strategy for $z=0.45$ and $z=0.5$.

Figure 4: Probation and Differentiation model: Manager's message strategy for intermediate values of $z$

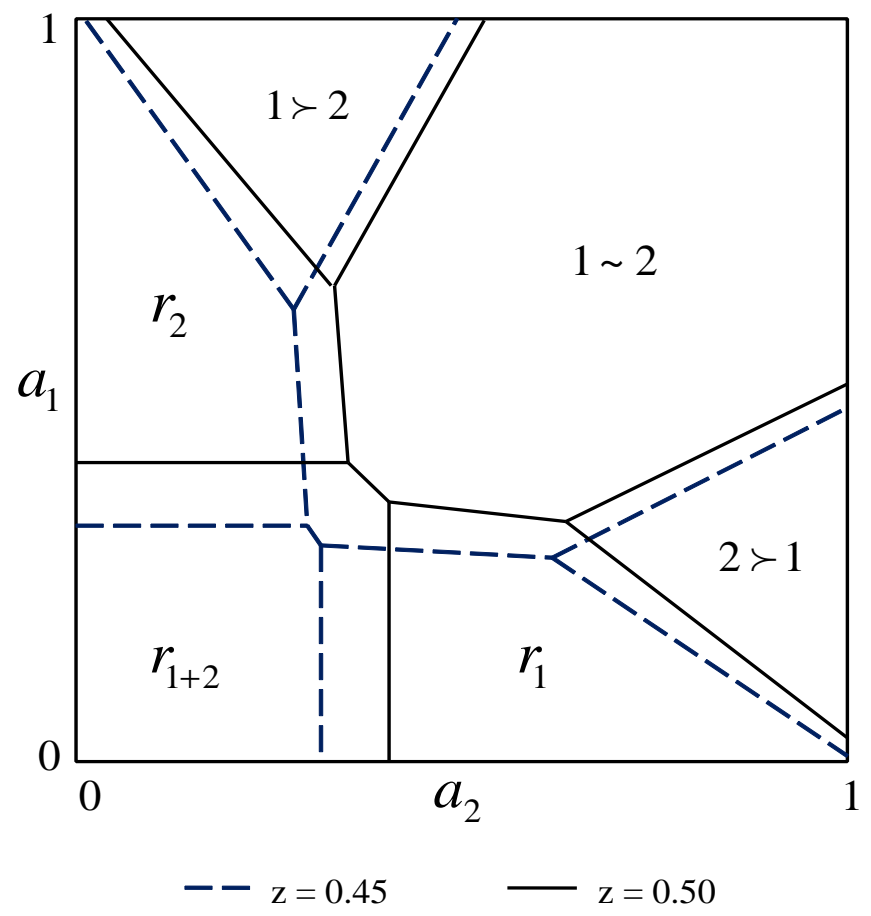


As in the previous case the manager only differentiates between employees if one employee is really able while the other is really unable. The main difference between Figure 4 and Figure 3 is that for $z>\underline{z}$ the manager sometimes chooses to replace only one employee. As z increases, it becomes more costly to keep a low ability worker just for the purpose of differentiation. The manager only chooses to keep both employees and differentiate if one is really able while the other has a much lower ability but is not completely unable. More specifically, from Figure 4 it follows that the manager never keeps an employee with an ability of zero. Altogether, also in this combined model we observe that the manager treats the employees equally for a wide range of abilities.

\subsection{Commitment}

Let us finally analyze the case in which the manager can commit herself to a probation and differentiation strategy. We assume that the probation strategy describes an ability threshold $a_{C}^{*}$ an employee must pass to stay in the company. More specifically, if $a_{i}<a_{C}^{*}$, then employee $i$ is replaced by an employee with expected ability $z$. The differentiation strategy is relevant if $a_{1}>a_{C}^{*}$ and $a_{2}>a_{C}^{*}$. Then, the manager may reveal that one employee is more able than the other, or she may abstain from such a comparison. As before, we limit ourselves to three messages: $m=1 \succ 2$ if $a_{1}>$

$t_{C} a_{2} ; m=2 \succ 1$ if $a_{1}<\frac{1}{t_{C}} a_{2}$ and $m=1 \sim 2$ if $\frac{1}{t_{C}} a_{2} \leq a_{1} \leq t_{C} a_{2}$, all messages conditional on $a_{1}>a_{C}^{*}$ and $a_{2}>a_{C}^{*}$. The manager's HRM strategy under commitment is characterized by two parameters $a_{C}^{*}$ and $t_{C}$. The equilibrium values of $a_{C}^{*}$ and $t_{C}$ maximize the manager's expected payoff.

As the game of the previous section, the present game cannot be solved analytically. Therefore, we again have to rely on a numerical analysis. Figure 5 presents for $z=0.5$ the optimal message strategy under commitment.

In general, Figure 5 confirms our findings of the previous sections. Under commitment, the requirements for an employee to stay are much harsher than in the absence of commitment. Moreover, the manager differentiates for a much wider range of parameters. If we only consider the cases where both employees are kept, then the probability of differentiation if $z=0.50$ is about 0.57 under commitment, while in the absence of commitment it is about 0.34. Most importantly, the set of parameters for which the manager keeps both employees and does not differentiate is much smaller under 
Figure 5: Probation and Differentiation model: Manager's message strategy under commitment $(z=0.50)$

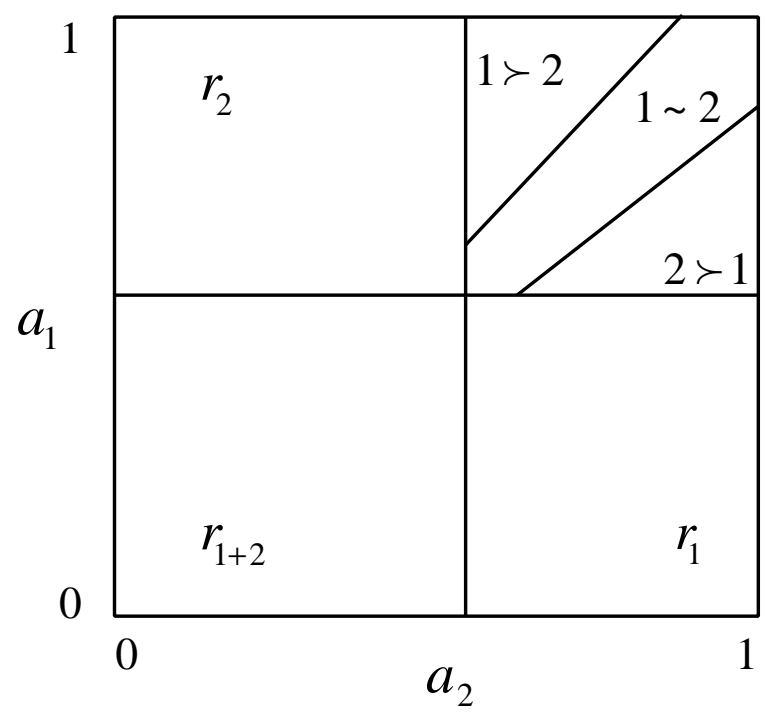

commitment than in the absence of commitment (see Table 2).

\begin{tabular}{ccc}
\hline \hline \multicolumn{3}{c}{ Table 2: Probability that the manager keeps both } \\
& employees and does not differentiate \\
\hline \hline $\boldsymbol{z}$ & Commitment & No Commitment \\
0.0 & 0.22 & 0.73 \\
0.1 & 0.21 & 0.73 \\
0.2 & 0.19 & 0.72 \\
0.3 & 0.16 & 0.68 \\
0.4 & 0.12 & 0.61 \\
0.45 & & 0.41 \\
0.5 & 0.09 & 0.37 \\
\hline \hline
\end{tabular}

All in all, our results demonstrate that formulating requirements for human resource management practices in advance has important consequences. On the one hand it leads to stricter criteria about which employees should be offered a permanent position. On the other hand, these written guidelines should offer sufficient room to differentiate. 


\section{Conclusion}

This paper has studied the role of pre-determined rules for HRM policies. We have considered a model in which HRM decisions affect employees' self-images and thereby their motivation. We have shown that in the absence of rules, managers are too reluctant to differentiate between employees on the basis of their abilities. Besides managers tend to shy away from firing employees on probation. Finally, we have shown that an organization benefits from committing to strict rules for two common HRM practices.

\section{Appendix}

In this Appendix we relax the assumption that the worker's ability is uniformly distributed. Suppose that the worker's ability, $a$, is drawn from a distribution $g(a)$ on $[0,1]$. Furthermore, we consider a more general payoff functions. Output $y$ is a function of effort and ability, $y=f(e, a)$. We assume that $f_{e}>0, f_{e e}<0, f_{a}>0$, and that effort and ability are complements, $f_{e a}>0$. To keep the analysis tractable, we consider the probation model with only one worker. The timing of the probation model is as follows. First the manager decides whether to keep the worker or to replace him, $m \in\{K, R\}$. Second, if the worker receives $m=K$, he decides how much effort to exert. If the worker receives $m=R$, then the worker is replaced and his utility equals zero.

Suppose that the manager's retention rule is: Keep the worker if $a \geq a^{*}$ and replace him otherwise. First, suppose that the worker is retained $(m=K)$. Then the worker's utility is given by $E[\lambda f(e, a)-c(e) \mid m=K]$. The costs of effort are $c(e)$, with $c_{e}>0$ and $c_{e e}>0$. Let $e^{*}$ be the worker's effort choice if $m=K$. The effort choice $e^{*}$ follows implicitly from

$$
\lambda f_{e}\left(e^{*}, \widehat{a}(K)\right)-c_{e}\left(e^{*}\right)=0
$$

where $\widehat{a}(K)$ is the expectation of $a$ conditional on message $K$. Using the implicit function theorem we can determine

$$
\frac{\partial e^{*}}{\partial a}=-\frac{F_{a}}{F_{e}}=-\frac{\lambda f_{e a}}{\lambda f_{e e}-c_{e e}}
$$

we know that $f_{e a}>0, f_{e e}<0$ and $c_{e e}>0$. This implies that $\frac{\partial e^{*}}{\partial a}>0$. 
Second, suppose that the worker is replaced $(m=R)$. Then the newcomer knows that his expected ability equals $z$, and he will choose the effort level that maximizes his utility function. Let $e^{z}$ be the newcomer's effort choice. The effort choice $e^{z}$ follows implicitly from

$$
\lambda f_{e}\left(e^{z}, z\right)-c_{e}\left(e^{z}\right)=0
$$

The next step is to determine the threshold value $a^{*}$. The payoff of the manager equals $(1-\lambda) f(e, a)$. The optimal effort level $e^{*}$ of a worker who obtains $m=K$ follows implicitly from equation (16). At $a=a^{*}$, the manager is indifferent between keeping the worker and replacing him. This means that $a^{*}$ solves

$$
(1-\lambda) f\left(e^{*}, a^{*}\right)=(1-\lambda) f\left(e^{z}, z\right)
$$

We can show that $a^{*}<z$. We show this by contradiction. Suppose that $a^{*}=z$. Then a worker who receives $m=K$ knows that his ability will be between $z$ and 1 , implying that $\widehat{a}(K)>z$. From equation (17) we know that the larger the expected ability is, the higher the exerted effort is. This means that $e^{*}>e^{z}$ if $a^{*}=z$. An implication is that the left-hand side of (18) is larger than the right-hand side if $a^{*}=z$. To make the left-hand side and the right-hand side equal, it must hold that $a^{*}<z$.

Next, suppose that the manager can commit to retention rule: Keep the worker if $a \geq a_{C}^{*}$, replace otherwise. If a worker is retained $(m=K)$, then the worker's choice of effort $e_{C}^{*}$ follows (implicitly) from

$$
\lambda f_{e}\left(e_{C}^{*}, \widehat{a_{C}}(K)\right)-c_{e}\left(e_{C}^{*}\right)=0
$$

The next step is to determine $a_{C}^{*}$. The threshold value $a_{C}^{*}$ follows from the following first order condition

$$
\begin{aligned}
E \Pi & =G\left(a_{C}^{*}\right) f\left(e^{z}, z\right)+\left(1-G\left(a_{C}^{*}\right)\right) f\left(e_{C}^{*}, a_{C}^{*}\right) \\
\frac{\partial E \Pi}{\partial a_{C}^{*}} & =g\left(a_{C}^{*}\right)\left(f\left(e^{z}, z\right)-f\left(e_{C}^{*}, a_{C}^{*}\right)\right)+\left(1-G\left(a_{C}^{*}\right)\right)\left(f_{a_{C}^{*}}\left(e_{C}^{*}, a_{C}^{*}\right)+f_{e_{C}^{*}}\left(e_{C}^{*}, a_{C}^{*}\right) \frac{\partial e_{C}^{*}}{\partial a_{C}^{*}}\right)=0
\end{aligned}
$$

We can show that $a_{C}^{*}>a^{*}$ by contradiction. Suppose that $a_{C}^{*}=a^{*}$, then according to equation (18) $a^{*}$ is chosen such that $f\left(e_{C}^{*}, a_{C}^{*}\right)=f\left(e^{z}, z\right)$. An implication is that 
the first part of the first order condition equals zero if $a_{C}^{*}=a^{*}$. The second part of the first order condition is positive. Hence if $a_{C}^{*}=a^{*}$ then $\frac{\partial E \Pi}{\partial a_{C}^{*}}>0$. This means that $a_{C}^{*}$ will be larger than $a^{*}$.

If we assume that the worker's utility function if $m=K$ equals $E\left[a e-\frac{1}{2} e^{2} \mid m=K\right]$ then we can additionally show that if the manager can commit to the retention rule that $a_{C}^{*}>z$. If a worker is retained $(m=K)$, then the worker's choice of effort is $e=\widehat{a_{C}}(K)=\frac{\int_{a_{C}^{*}}^{1} a \cdot g(a) d a}{\int_{a_{C}^{*}}^{1} g(a) d a}$. The next step is to determine $a_{C}^{*}$.

$$
\begin{aligned}
E \Pi & =G\left(a_{C}^{*}\right) z^{2}+\left(1-G\left(a_{C}^{*}\right)\right)\left(\widehat{a_{C}}(K)\right)^{2} \\
\frac{\partial E \Pi}{\partial a_{C}^{*}} & =g\left(a_{C}^{*}\right)\left(z^{2}-\left(\widehat{a_{C}}(K)\right)^{2}\right)+2\left(1-G\left(a_{C}^{*}\right)\right) \widehat{a_{C}}(K) \frac{\partial \widehat{a_{C}}(K)}{\partial a_{C}^{*}}=0
\end{aligned}
$$

From this inequality we can derive that $\widehat{a_{C}}(K)>z$. The second part of the first order condition is positive. The reason is that a worker's expected ability increases in the threshold the manager uses. A worker knows that if he receives the message $K$, that his ability is at least equal to the threshold. Hence, the higher the threshold is that the manager uses, the higher the expected ability of the worker is. Given that the second part is positive, equation (19) can only hold if the first part of the equation is negative. This implies that $z<\left(\widehat{a_{C}}(K)\right)$.

The next step is to show that $a_{C}^{*}>z$. This does not immediately follow from the first order condition. Applying Leibniz rule, we find that $\frac{\partial \widehat{a_{C}}(K)}{\partial a_{C}^{*}}=-\frac{a_{C}^{*} g\left(a_{C}^{*}\right)}{G\left(a_{C}^{*}\right)}+$ $\widehat{a_{C}}(K) \frac{g\left(a_{C}^{*}\right)}{G\left(a_{C}^{*}\right)}$. If we substitute this into equation (19) we get

$$
\frac{\partial E \Pi}{\partial a_{C}^{*}}=g\left(a_{C}^{*}\right)\left(z^{2}-\left(\widehat{a_{C}}(K)\right)^{2}\right)+\frac{1-G\left(a_{C}^{*}\right)}{G\left(a_{C}^{*}\right)}\left(-2 \widehat{a_{C}}(K) a_{C}^{*} g\left(a_{C}^{*}\right)+2\left(\widehat{a_{C}}(K)\right)^{2} g\left(a_{C}^{*}\right)\right)=0
$$

First suppose that $a_{C}^{*}=z$, then we can replace $a_{C}^{*}$ with $z$ in the first order condition

$$
\begin{aligned}
& g(z)\left(z^{2}-\left(\widehat{a_{C}}(K)\right)^{2}\right)+\frac{1-G(z)}{G(z)}\left(-2 \widehat{a_{C}}(K) z g(z)+2\left(\widehat{a_{C}}(K)\right)^{2} g(z)\right) \\
= & g(z) \frac{1-G(z)}{G(z)}\left(-2 \widehat{a_{C}}(K) z+2\left(\widehat{a_{C}}(K)\right)^{2}+\frac{G(z)}{1-G(z)}\left(z^{2}-\left(\widehat{a_{C}}(K)\right)^{2}\right)\right)
\end{aligned}
$$

For $G(z) \leq \frac{1}{2}$ the expression between the brackets is positive. Hence, for $a_{C}^{*}=z$ we find that $\frac{\partial E \Pi}{\partial a_{C}^{*}}>0$. This implies that $a_{C}^{*}>z$. 


\section{References}

[1] Ackerman, P. L., Beier, M. E., and Bowen, K. R. (2002). What we really know about our abilities and our knowledge. Personality and Individual Differences, vol. 33 , pp. 587-605.

[2] Aronson, E., Wilson, T.D., and Akert, A.M. (2005). Social Psychology (5th ed.). Upper Saddle River, NJ: Prentice Hall.

[3] Benabou, R. and Tirole, J. (2003). Intrinsic and Extrinsic Motivation. Review of Economic Studies, vol. 70, pp. 489-520.

[4] Bewley, T. F. (1999). Why wages don't fall during a recession. Cambridge, MA: Harvard University Press.

[5] Brickley, J. A., Smith, C. W., and Zimmerman, J. L. (2009). Managerial Economics and Organizational Architecture (5th ed.). Irwin: McGraw-Hill.

[6] Crutzen, B., Swank, O. H., and Visser, B. (2010). Confidence Management: on Interpersonal Comparisons in Teams.

[7] Ederer, F. (2010). Feedback and Motivation in Dynamic Tournaments. Journal of Economics and Management Strategy, vol. 19(3), pp. 733-769.

[8] Ertac, S. (2005). Social Comparisons and Optimal Information Revelation: Theory and Experiments.

[9] Ishida, J. (2006). Optimal Promotion Policies with the Looking-Glass Effect. Journal of Labor Economics, vol. 24, pp. 857-878.

[10] Kruger, J. (1999). Lake Wobegon be gone! The "below-average effect" and the egocentric nature of comparative ability judgements. Journal of Personality and Social Psychology, vol. 77 (2), pp. 221-232.

[11] Kydland, F., and Prescott, E. C. (1977). Rules Rather than Discretion: The Inconsistency of Optimal Plans. Journal of Political Economy, vol. 85(3), pp. 47391.

[12] Prendergast, C., and Topel, R. (1993). Discretion and bias in performance evaluation. European Economic Review, vol. 37(2-3), pp. 355-365 
[13] Prendergast, C., and Topel, R. (1996). Favoritism in Organizations. Journal of Political Economy, vol. 104(5), pp 958-78.

[14] Swank, O. H., and Visser, B. (2007). Motivating Through Delegating Tasks or Giving Attention. Journal of Law, Economics and Organization, vol. 23, pp. 731742. 